\title{
$\alpha_{\mathrm{k}}$
}

Research \& Methods

ISSN 1234-9224, e-ISSN 2544-0799

Vol. 29 (1, 2020): 29-53

The Ohio State University Libraries

Columbus, Ohio, USA

Institute of Philosophy and Sociology

Polish Academy of Sciences, Warsaw, Poland

www.askresearchandmethods.org

https://doi.org/10.18061/ask.v29i1.0003

\section{Longitudinal Surveys for Comparative Analyses of Poland and Romania: The Polish Panel Survey (POLPAN), 2013-2018 and the Romanian World Values Survey Panel (WVS-RO), 2012-2018}

\author{
Kazimierz M. Slomczynski \\ Polish Academy of Sciences and The Ohio State University \\ Malina Voicu \\ Romanian Academy, Research Institute for Quality of Life \\ Joshua K. Dubrow \\ Polish Academy of Sciences \\ Simona Maria Stănescu \\ Romanian Academy, Research Institute for Quality of Life

\section{Irina Tomescu-Dubrow} \\ Polish Academy of Sciences
}

\begin{abstract}
If researchers wish to use surveys to understand the attitudes and behaviors of those who live in former State Socialist countries, they face a research landscape densely populated by cross-sectional studies. Panel surveys with individuals as the units of analysis, which are ideal for understanding change within people over time, are rare. As a service to researchers, this article presents possibilities for cross-national comparison via two sets publicly available panel data: the Polish Panel Survey POLPAN (focusing on its 2013 and 2018 waves) and the novel Romanian World Values Survey Panel RO-WVS (2012 and 2018 waves), which is the only panel version of World Values Survey (WVS). We present the research designs of each, and explore their ex-post harmonization. Conceptual overlap between these sources occurs mainly (but not only) with major socio-demographics and with political attitudes and behavior, including interest in politics, political participation, democratic values, and institutional trust. Whereas POLPAN is relatively well known, we argue that RO-WVS panel stands out as a unique resource that provides data on the


dynamic nexus between social structure and cultural context. Keeping RO-WVS alive for a long period would help researchers to understand Romanian society in the European context, and provide for future comparisons between it and its neighbors.

Acknowledgements: This research was supported by the National Science Centre, Poland for the project "Multidimensional Biographies and Social Structure: Poland 19882018" (UMO-2017/25/B/HS6/02697). We thank llona Wysmulek for her comments on an earlier draft, and Zbigniew Sawinski for his dedicated work on preparing and maintain the POLPAN datasets. This article is a result of the cooperation between the Institute of Philosophy and Sociology of the Polish Academy of Sciences and the Research Institute for Quality of Life, Romanian Academy.

\section{LONGITUDINAL SURVEYS FOR COMPARATIVE ANALYSES OF POLAND AND ROMANIA: THE POLISH PANEL SURVEY (POLPAN), 2013-2018 AND THE ROMANIAN WORLD VALUES PANEL (WVS-RO), 2012-2018}

To understand the functioning of post-socialist society, a dynamic, longitudinal framework of analysis has clear benefits. Whereas cross-sectional survey data provide a snapshot of society that could, with some contextual explanation and as part of a time series, provide interesting observations about societal change, analyses of panel data provide insight into the impact that social structure and changes thereof have for peoples' lives: one can examine the extent to which within-person variation (i.e. the change within people over time) is greater than between-person variation (i.e. differences between people in given times). Moreover, a dynamic framework, where the same individuals' structural and psychological characteristics are measured repeatedly, opens the possibility to also understand how people influence social structure while being influenced by it. Specifically, in addition to treating the position of individuals in the social structure as a determinant of their attitudes and behaviors, researchers look to panel data to test hypotheses about how these past and current resources impact people's achievements, their placement in the social structure, and their political attitudes and behaviors. ${ }^{1}$

From a methodological point of view, advantages of panel data over time series or cross-section data include, among others, more accurate inference of model parameters, thanks to more degrees of freedom and less collinearity, the possibility to control for omitted variables effects, and testing more complex behavioral hypotheses (Hasio 2007, 2014).

Panel surveys with individuals as the units of analysis and conducted in the post-socialist countries are rare. ${ }^{2}$ In Central and Eastern Europe (CEE), the Polish Panel Survey POLPAN 1988-2018 (polpan.org) is the longest continually run 
study of this type. Romania, despite a rich tradition of survey research since the 1990s, has no such equivalent. However, the country features the recent and novel WVS Romanian Panel of 2012 and 2018, which is the only WVS panel in CEE post-communist countries. ${ }^{3}$ If scholars wish to compare Poland and Romania using panel surveys, the option of using these two datasets is evident.

This article serves as a resource for researchers interested in longitudinal, comparative panel survey analyses of Poland and Romania, as it provides a description of item overlap between POLPAN and the Romania WVS Panel studies and some discussion of harmonization of these panels. The description is structured as follows. First, for both POLPAN and RO-WVS Panel, we present the intellectual basis, topic coverage, methods of survey administration, and structure of the data. Then, we present the topic and item overlap between these surveys. We then discuss ex-post harmonization of these surveys, with examples. We conclude with a discussion on how comparative panel surveys can aid the pursuit of crossnational research in post-socialist states nowadays.

\section{Polish Panel Survey POLPAN 1988-2018}

\section{Intellectual Basis and Survey Topics}

We provide here a summary of the intellectual history and survey topics of POLPAN, while noting that a longer discussion is available elsewhere (Slomczynski et al 2015; see also Tomescu-Dubrow et al 2018). POLPAN focuses on long-term changes in the social structure. Classic and modern work in stratification in Poland and abroad considers social structure in the framework of rational action and the life course. Following this tradition, POLPAN is designed to provide insights into conceptualizing social structure in terms of social classes and biographies, and addresses the topic of how to operationalize such concepts in a panel study. POLPAN is built, in part, on theories that emphasize both "structure" and "agency", and applying these theories to data that represent lives of the panel respondents. POLPAN enables scholars to analyze distinct features of social and political segmentation in which individual biographies play an active role. Instead of debating the primacy of "structure vs. agency," then, analyses can focus on the capacity of individuals to act and make their choices that are reflected in biographies, and influenced, to some measurable extent by structural conditions.

There is an extensive list of research topics for which POLPAN is well suited (Slomczynski et al 2015). Among many others, the study includes the old and new elements in the social structure, the impact of individuals' location in the social structure on their support for Poland's transformation, and the relationship between social structure and political behavior. 


\section{Survey Administration}

POLPAN has always drawn on, and sought to expand upon, the main currents in survey methodology in terms of large scale survey practice, among other things, data quality, including process management (e.g. Groves and Lyberg, 2010, Lyberg and Stukel 2010, Lyberg and Weisberg 2016). Since 1988, the main interview mode has been pen and paper face-to-face interviews (PAPI), although sometimes sub-samples of panelists were also approached differently (e.g. in 2013, a sub-sample of respondents first interviewed in 1988 were approached also via postal questionnaires). In 2018, the switch to computer assisted interviewing CAPI was considered, but given potential risks of lower data quality following change in interview mode the decision was to continue with PAPI. This decision was influenced by the experiences that other panels, the British Household Panel Survey (BHPS) and the German Socio-Economic Panel (SOEP) in particular, made when moving from PAPI to CAPI midway in the study's lifecycle. Both report difficulties, especially for the first wave under the new data collection mode. In BHPS for example, interviewers on CAPI truncated their verbatim entries for respondents' occupational descriptions, which in turn led to variations in the post field coding carried out using these responses (Laurie 2003). While BHPS did not test for mode effects explicitly (Laurie 2003), SOEP did so using an experimental design (Schräpler, Schupp, and Wagner, 2010). Regarding downsides, SOEP reports that in the $1^{\text {st }}$ wave of CAPI use, CAPI had the highest rate of implausible values in the questionnaire, and that CAPI interviews yielded higher item-nonresponse on income than PAPI interviews (Schräpler et al. 2010).

From the start of POLPAN, oversight of data collection and processing have been the purview of the Principal Investigators and the Center of Sociological Research (CSR, known in Polish as ORBS) at the Institute of Philosophy and Sociology of the Polish Academy of Sciences. CSR maintains a network of interviewers from 22 locations in Poland, whom they train and supervise together with regular members of the POLPAN team. Each POLPAN wave involves several questionnaire versions, depending on the features of samples within a wave, however, the bulk of items are common across versions (e.g. the questionnaire for the renewal sample of young added to the core panelists every wave since 1998 contains some additional questions about respondents' job history). All questionnaires are pretested prior to fielding. CSR, in collaboration with POLPAN team members and, sometimes, external research units (as was the case in the 2013 wave, for example), implement measures of fieldwork control for each wave. 
The POLPAN panel study currently consists of seven survey waves conducted consecutively at five years intervals, most recently in 2018. POLPAN waves comprise panelists, and starting with 1998, renewal samples of young. Basic information about samples for POLPAN waves 1-7 is provided in Table 1.

The initial survey, known currently as POLPAN 1988, was carried out in late "Real Socialism" on a nationally representative sample of 5,817 men and women of working age (ages 21 to 65). Respondents for POLPAN 1988 were randomly selected from a nationwide microsensus carried out by the Public Opinion Research Center (CBOS) in 1986 (for more details on wave 1 sampling, see polpan.org/en/ data-and-documentation/methodology/1988-2/). These people were interviewed at the end of 1987 and the beginning of 1988, on a broad set of issues pertaining to social inequality, involvement in political organizations, and attitudes toward state welfare provisions and the then-existing socialist system. Respondents of 1988 form the core panel sample of POLPAN.

The second wave was conducted in 1993. Because of financial constraints, rather than returning to all participants of the 1988 study, POLPAN 1993 randomly selected a sub-sample of 2500 women and men, 2,259 of whom were successfully interviewed. Substantively, the wave focused primarily on attitudinal and behavioral aspects of radical social change that had taken place in the period between the two studies.

POLAPN's third wave was carried out in 1998, on a total sample of 2,135 adult Poles, of whom part were panelists (i.e. respondents who took part in the 1988 and 1993 studies) and another part were young respondents first selected in 1998. The panel sample comprises 1,752 men and women who in 1998 were aged 31 to 65 years. The so-called renewal sample (random sample of young) comprises Poles who in 1998 were aged 21 to 30 years $(n=383)$. In addition to the core items devoted to the study of social structure and its transformation, POLPAN 1998 included questions on voting behavior in the 1993 and 1997 parliamentary elections, as well as an extensive battery of questions on support for democratic values and norms. 
Table 1. Sample Sizes of the Consecutive Waves of the Polish Panel Survey, POLPAN 1988-2018

\begin{tabular}{lccccccc}
\hline & \multicolumn{7}{c}{ Waves } \\
& $\begin{array}{c}\text { First } \\
(1987-1988)\end{array}$ & $\begin{array}{c}\text { Second } \\
(1993)\end{array}$ & $\begin{array}{c}\text { Third } \\
(1998)\end{array}$ & $\begin{array}{c}\text { Fourth } \\
(2003)\end{array}$ & $\begin{array}{c}\text { Fifth } \\
(2008)\end{array}$ & $\begin{array}{c}\text { Six } \\
(2013)\end{array}$ & $\begin{array}{c}\text { Seven } \\
(2018)\end{array}$ \\
\hline Raw sample & 5,817 & 2,259 & 2,135 & 1,699 & 1,756 & 2,196 & 2,161 \\
Panel sample & - & $2,259^{\mathrm{a}}$ & 1,752 & $1,474^{\mathrm{b}}$ & $1,216^{\mathrm{b}}$ & $1,699^{\mathrm{b}}$ & $1,875^{\mathrm{b}}$ \\
Renewal samples & - & - & $383^{\mathrm{c}}$ & $225^{\mathrm{d}}$ & $540^{\mathrm{d}}$ & $494^{\mathrm{d}}$ & $286^{\mathrm{d}}$ \\
\hline
\end{tabular}

${ }^{\text {a }}$ Contains 2,092 cases from the randomly selected subset of the 1988 sample and 167 cases from the same sample over-representing people with higher education and involved in self-employment (in 1988). The composition of the total 1993 sample $(n=2,259)$ mirrors the 1993 population better than the 2,092 cases from the randomly selected subset of the 1988 sample.

${ }^{b}$ Contains cases from the renewal sample of the previous wave.

c Random sample of residents of Poland who in 1998 were 21-30 years old.

${ }^{d}$ Random sample of residents of Poland aged $21-25$ in a given wave year.

Samples of the fourth, fifth, sixth, and seventh waves of POLPAN - conducted in 2003, 2008, 2013, and 2018, respectively - consist of Polish residents who took part in previous POLPAN waves (i.e. panel respondents), and respondents from the young cohort, aged twenty-one to twenty-five in a given POLPAN wave (i.e. renewal samples). Whenever POLPAN adds renewal samples, selection of new respondents involves simple random sampling using the PESEL register (Powszechny Elektroniczny System Ewidencji Ludności, The Universal Electronic System for Registration of the Population). The total number of respondents interviewed at least once for the POLPAN study is 7,799 (5,817 respondents in wave one, plus respondents in the renewal samples).

Given the correspondence to the Romanian data, we pay closer attention to samples of POLPAN 2013 and 2018, respectively. In 2013, thanks to generous funding from the Polish National Science Centre, we were able to reapproach panelists who „skipped" one or more surveys prior to 2013. ${ }^{4}$ As Table 2 shows, in POLPAN 2018 (wave seven), there are four panel samples and a renewal sample of young adults residents of Poland. The first panel sample contains respondents from all waves $(n=544, \mathrm{RR}=83 \%) .{ }^{5}$ Two next panel samples include respondents that were re-interviewed prior to 2013 , but differ with respect to the entry wave (for those starting in 1987/1988, $\mathrm{n}=596$, and for those starting in 1998 or 2003, $\mathrm{n}=448$ ). For most recent panelists, first interviewed in 2013, $\mathrm{n}=277$. For all these samples RR is above $70 \%$. The renewal sample covers young people aged $21-25$ in 2018 (i.e. born between 1993 and 1997). The number of realized interviews is $286(\mathrm{RR}=54 \%)$. 
Table 2. Sample Composition of POLPAN 2018 (Wave Seven)

\begin{tabular}{lcr}
\hline Composition of the 2018 Sample & $\mathrm{N}$ & \multicolumn{1}{c}{$\%$} \\
\hline Panelists first interviewed in 1987/1988 and re-interviewed in all waves & 544 & 25.5 \\
$\begin{array}{l}\text { Panelists first interviewed in 1987/1988, who were not re-interviewed in all } \\
\text { subsequent waves, but were interviewed in 2013 }\end{array}$ & 596 & 27.6 \\
$\begin{array}{l}\text { Panelists first interviewed in 1998 or 2003, and re-interviewed in 2008, or 2013, } \\
\text { or both }\end{array}$ & 458 & 21.2 \\
Most recent panelists, first interviewed in 2013 & 277 & 12.8 \\
Renewal sample of Poles aged 21-26 in 2018 & 286 & 13.2 \\
Total & 2,161 & 100.0 \\
\hline
\end{tabular}

Finally, we note that in POLPAN, wave-specific samples are representative of the country's age distribution at the time of the survey. Researchers can also analyze POLPAN waves as stand-alone, cross-sectional datasets. ${ }^{6}$ The selected POLPAN waves are available from the Polish Social Data Archive (ads.org.pl) and the integrated data set from polpan.org.

\section{The Romanian World Values Survey Panel 2012 - 2018}

\section{Intellectual Basis and Survey Topics}

The history of WVS is closely connected with modernization theory, aiming at providing empirical evidences for the link between economy and culture. The whole project developed around Inglehart's theory of postmaterialist value change in advanced democracies, which points out the relationship between economic development and the shift from materialist to postmaterialist value orientations (Inglehart, 1997). According to Inglehart, cultural change goes hand in hand with economic change: traditional societies having scarce resources means that people are more concerned with the satisfaction of their basic needs and thus give precedence to behaviors and values meant to insure individual survival, including religion, obedience, and traditional gender roles. Economic development brought material security, increasing the likelihood of survival, and freeing the individual from constrains imposed by scarcity (Inglehart, 2018). A cultural change occurred once the likelihood of survival changed, postmaterialist values spreading among those living in highly advanced societies, who took survival for granted. Postmaterialist value orientation deals with tolerance, support for gender equality, concerned for environment protection and self-expression. The revised modernization theory proposed two cultural dimensions of cultural variation around the world, traditional versus secular-rational values and survival versus self-expression values (Inglehart and Welzel, 2005). 
The questionnaire fielded by WVS includes questions tapping the core values orientations, materialism / postmaterialism, tolerance, support for gender equality, religiosity, inter-individual trust and confidence in institutions, as well as support for democracy, civic and political participation and subjective wellbeing. Several socio-demographic variables are included, providing information about respondent's gender, age, education income, self-assessment of social status, some variables collecting data about parental background (mothers' and fathers' education and occupation). The WVS has collected data every five to seven years since 1982, covering more than 100 societies in seven successive waves. Beside the core questions, mentioned above, which are fielded every time, each wave includes some specific questions tapping societal issues relevant for the particular moment of the data collection (e.g. attitudes towards immigrants, ageism and population ageing).

\section{Survey Administration}

WVS is fielded as repeated cross-sectional surveys aiming to maximize the comparability across countries in each wave and to provide a solid background for the study of cultural changes over time. Therefore, the main focus, from methodological point of view, is to increase standardization within each wave preserving comparability with previous waves as much as possible. This concerns the structure of the questionnaire, the translation procedure, as well as the sampling and weighting design. In 2012 and 2018 in Romania WVS was fielded as a panel survey due to theoretical and methodological reasons. Theoretical reasons pertain to the hypotheses of the change in attitudes because economic activity picked up in this period, driven by the gradual improvement in the domestic demand, led by the private consumption, and by exports, mainly to the EU. Methodologically, including a panel component into WVS was a challenging innovation.

The methodology of data collection and data processing followed strictly the rules set up by the WVS international team of coordination. Translation followed the same procedure in 2012 and 2018, the new items that were not used in the previous waves of the survey being translated by a team composed of two translators and one adjudicator, while in case of core items, the translation used in 2012 was used in 2018. The data were collected for both waves in face-to-face computer assisted interviews (CAPI) by the same data collection agency. Data cleaning and data processing was carried out by the Romanian social values study group and the pooled dataset is available on the website: romanianvalues.ro. 
Structure of the Data

WVS 2012 and 2018 Romanian samples include only adults over 18 years old. The upper age cut-off in 2012 was 85 years old, while in 2018 there was no upper age cut-off. The sampling design of both waves employed five strata (region, size of locality, voting precinct, household, and individual) and 150 sampling points, selected from the list of voting precincts and based on two stratification factors: socio-cultural area (18 areas) and locality (size by level of economic development). Individuals were selected within the voting precinct based on the Kish grid and using next birthday as selection criteria within the household. The minimum response rate computed based on WAPOR/AAPOR definition is of 0.68 in 2012 and 0.54 in 2018. A weight variable adjusting for region, gender age and type of locality is available in the pool dataset, for both waves.

The WVS panel started in Romania with the 2012 wave, although WVS was fielded there before. The 2012 sample comprised 1503 cases, being representative for the adult population (aged 18 and above) of Romania. The questionnaire includes the standard core questions regarding postmaterialist value orientations, religiosity, support for democracy, political participation, tolerance, gender role attitudes, generalized trust, confidence in institutions and wellbeing plus some specific questions tapping the ageism and electoral integrity.

The WVS 2018 sample includes 1257 cases, among them 561 being part of the panel sample and 696 belonging to the renewal sample. Although the time span between the two waves is of five years, the attrition rate is $68 \%$, in most of the cases the interviewer could not reach the respondent from the previous wave because of the high residential mobility in Romania. We should mention here that Romania recorded a very high external migration after the accession to EU (OECD, 2019), which makes very difficult to reach respondents after five years. Besides the core items, repeated in each wave of WVS, the 2018 questionnaire includes several questions regarding attitudes towards immigrants and attitudes towards corruption.

Table 3. Sample Sizes of the Consecutive Waves of the WVS Romania, 2012-2018

\begin{tabular}{lcc}
\hline & WVS 2012 & WVS 2018 \\
\hline Raw sample & 1503 & 1257 \\
Panel sample & 561 \\
Renewal sample & 696 \\
\hline Attrition rate & $68 \%$ \\
\hline
\end{tabular}




\section{Topic and Item Overlap between POLPAN 2013-2018 and WVS-RO Panel 2012-2018}

From a theoretical point of view, a panel survey on values is an important and useful way to study the relations between culture and social structure. A panel survey allows the investigation of the causal impact of individual socio-demographic factors, such as employment status, training and education, household structure or marital status, to mention only some of them, on values and attitudes during recent socio-political transformation. A list of variables suitable for crosscountries comparisons based on POLPAN and RO-WVS is shown in Table 4, and in Appendix.

Table 4. Topics in POLPAN (2013-2018) and RO-WVS (2012-2018) suitable for cross-national comparisons

\begin{tabular}{lcc}
\hline \multirow{2}{*}{ Topics } & Poland & Romania \\
\cline { 2 - 3 } & Number of items and coded categoriesa \\
\hline Gender & Socio-demographics & \\
Year of birth, Age & $2-2$ & $1-2$ \\
Marital Status & $3-$ cont $^{\mathrm{b}}$ & $2-$ cont $^{\mathrm{b}}$ \\
Presence of Children in the Household & $2-5$ & $2-6$ \\
Living with Parents & $8-7^{\mathrm{c}}$ & $2-8$ \\
Educational attainment & $2-2^{\mathrm{c}}$ & $2-2(4)^{\mathrm{d}}$ \\
Employment status & $2-12$ & $2-9(8)^{\mathrm{d}}$ \\
Locus of employment & $7-8^{\mathrm{e}}$ & $2-8$ \\
\hline & $7-3^{\mathrm{e}}$ & $2-3$ \\
\hline Interest in Politics & & $2-4$ \\
Political Participation & $2-5$ & $10-3$ \\
Democratic Values & $7-2$ & $2-3$ \\
Institutional trust & $2-3$ & $3-4$ \\
Success in Life & $3-5$ & $2-10$ \\
Religiosity & $6-6$ & $2-7$ \\
Self-reported Health & $2-5$ & $2-4$ \\
\hline
\end{tabular}

a Categories without don't knows, difficult to say, and no answer.

b In years.

c From the table of all members of the respondent household.

d Number in parenthesis refers to the later wave.

e Inferred from set of items. 
The data from the two countries are potentially comparable, but since POLPAN and RO-WVS were not harmonized at the stage of design, harmonization procedures need to be implemented ex-post, that is, after the data have already been released (for a discussion of harmonization types, and the usefulness of ex-post harmonization, see, e.g. Granda and Blasczyk 2016; Slomczynski and Tomescu-Dubrow 2018). This presupposes transforming original (i.e. source) variables from each of the country-specific datasets into so-called target variables that are common for a dataset with information pooled across years and countries.

There are various reasons for why ex-post harmonization is needed. First, the number of relevant items in the questionnaires differs between the two countries. For example, from POLPAN data presence of children in the household can be inferred from the table of members in the household, constructed on the basis of several items. In RO-WVS in 2012 and 2018, respectively, a single question corresponds to the same variable. Cross-country differences in number of items appears for such variables as year of birth/age, employment status and locus of employment, political participation, and success in life.

Second, properties of source items vary between the Romanian and Polish surveys. For example, let us take scales and their number of categories of answers in the concrete instance of assessing the frequency with which respondents attend religious services in Poland, and in Romania, respectively.

POLPAN: Apart from special situations, like weddings or funerals, how frequently do you participate in church service? Answers: (1) almost never, not at all, (2) less frequently than once a month, (3) less frequently than once a week, but at least once a month, (4) usually once a week, or (5) more frequently than once a week.

RO-WVS: Apart from weddings and funerals, about how often do you attend religious services these days? Answers: (1) more than once a week, (2) once a week, (3) once a month, (4) only on special holy days, (5) once a year, (6) less often, (7) never, practically never.

An overview of items common across POLPAN 2013-2018 and RO-WVS 2012-2018 is available in the Appendix. Even a cursory glance at this information indicates that ex-post harmonization is an intrinsic step to preparing the data stemming from the two panel surveys for comparative analyses. 


\section{Three examples of harmonizing the data}

In Table 5, we provide frequency distributions for the items above, using 2013 data on POLPAN 2013-2018 panelists, and 2012 data on RO-WVS 2012-2018 panelists, respectively. The question is how to transform these frequencies for the categories presented in this table.

We provide three examples of constructing the target variable in metrics common for both countries, starting from similar work carried out within the Survey Data Recycling (SDR) project (e.g. Slomczynski, Jenkins, and TomescuDubrow et al. 2016). The first option is to convert the label of the ordinal scale into an intensity measure $d$, stemming from the cumulative percentage distribution, according to the formula:

$$
d=\sum_{i=1}^{n} X_{r}+X_{k}
$$

with values $k$ ranging from 1 (the highest value) to $n$, where $X_{k}$ is the percentage of values $k$, and $X_{r}$ is the lower bound of the cumulative distribution. In Table 5 we provide intervals of cumulative distribution with the lower bound $X_{r}$ and half of the interval $\left(X_{k} / 2\right)$, both pieces of information needed to compute the cumulative scores $d$ (column A). For Poland and Romania, the interpretation of these numbers is the same: they indicate what percentage of people attends religious services on the lower rate. Note, however, that the mean value of these scores for each country is 50. This means that researchers can use this transformation only for relative comparisons of individuals between countries, since in each country their location is internally standardized.

Complementarily, one can use a second scale: z-scores, for which the cumulative scores are the base (Table 5, column B). This non-linear transformation is achieved by adjustment of cumulative scores $d$ to the $z$-scores underlying the normal distribution. Thus $z$-scores inform about the distance of a given case from the mean. The distance is expressed in standard deviations, with sings indicating whether a given value is above or below the mean.

The third option of transformation in Table 5 deals with estimated frequencies of attending religious services in month metric. Unfortunately, labeling of answers is not precise and for some categories one has to assume an arbitrary number. For example, we assume that "more frequently than once a week" (POLPAN) and "more than once a week" (RO-WVS) are equivalent and correspond to the frequency of 12 per month, that is somewhere between 2 and 3 times per week (Table 5, column C). ${ }^{7}$ 
Table 5. Answers on the frequency of attending religious services in POLPAN and RO-WVS and proposed scales

\begin{tabular}{|c|c|c|c|c|c|c|c|}
\hline \multirow{3}{*}{$\begin{array}{l}\text { Ranking } \\
\text { from high } \\
\text { to low } \\
\text { intensity }\end{array}$} & \multirow{3}{*}{ Answers } & \multirow{3}{*}{ Percent } & \multirow{3}{*}{$\begin{array}{c}\text { Interval of } \\
\text { cumulative } \\
\text { distribution } \\
\%\end{array}$} & \multirow{3}{*}{$\begin{array}{c}1 / 2 \text { of the } \\
\text { length of } \\
\text { interval }\end{array}$} & \multicolumn{3}{|c|}{ Scales } \\
\hline & & & & & $\begin{array}{l}\text { Cumu- } \\
\text { lative } \\
\text { score } \\
\end{array}$ & $\begin{array}{c}\begin{array}{c}Z \text { score } \\
\text { for } \\
\mu=50\end{array} \\
\end{array}$ & $\begin{array}{c}\text { Frequency } \\
\text { per } \\
\text { month } \\
\end{array}$ \\
\hline & & & & & A & B & $\mathrm{C}$ \\
\hline \multicolumn{8}{|c|}{ POLPAN $(N=1820)$} \\
\hline 1 & $\begin{array}{l}\text { more frequently than once } \\
\text { a week }\end{array}$ & 6.8 & $100.0-93.2$ & 3.4 & 96.6 & 1.83 & $12.0 \mathrm{a}$ \\
\hline 2 & usually once a week & 47.4 & $93.2-45.8$ & 23.7 & 69.5 & 0.51 & 4.3 \\
\hline 3 & $\begin{array}{l}\text { less frequently than once } \\
\text { a week, but at least once } \\
\text { a month }\end{array}$ & 16.2 & $45.8-29.6$ & 8.1 & 37.7 & -0.31 & $1.5 b$ \\
\hline 4 & $\begin{array}{l}\text { less frequently than once } \\
\text { a month }\end{array}$ & 19.8 & $29.6-9.8$ & 9.9 & 19.7 & -0.85 & $0.5 \mathrm{c}$ \\
\hline 5 & almost never, not at all & 9.8 & $9.8-0$ & 4.9 & 4.9 & -1.65 & 0 \\
\hline \multicolumn{8}{|c|}{ RO-WVS (N = 561) } \\
\hline 1 & more than once a week & 6.4 & $100.0-93.6$ & 3.2 & 96.8 & 1.85 & $12.0 \mathrm{a}$ \\
\hline 2 & one a week & 27.0 & $93.6-66.6$ & 13.5 & 80.1 & 0.85 & 4.3 \\
\hline 3 & once a month & 14.6 & $66.6-52.0$ & 7.3 & 69.3 & 0.50 & 1.0 \\
\hline 4 & only on special holy days & 29.0 & $52.0-23.0$ & 14.5 & 37.5 & -0.32 & $0.5 d$ \\
\hline 5 & once o year & 4.8 & $23.0-18.2$ & 2.4 & 20.6 & -0.82 & 0.1 \\
\hline 6 & less often & 14.4 & 18.2.-3.8 & 7.2 & 11.0 & -1.22 & $0 e$ \\
\hline 7 & never, practically never & 3.8 & $3.8-0$ & 1.9 & 1.9 & -2.07 & 0 \\
\hline $\begin{array}{l}\text { a Assun } \\
\text { b Assun } \\
\text { c Assun } \\
\text { d Assun } \\
\text { e Roun }\end{array}$ & $\begin{array}{l}\text { ming attendance between } 2 \text { and } \\
\text { ming once a month for half a yea } \\
\text { ming every second month } \\
\text { ming six holy days } \\
\text { ided to } 0\end{array}$ & $\begin{array}{l}3 \text { times a w } \\
\text { and twice }\end{array}$ & month for half & a year. & & & \\
\hline
\end{tabular}

\section{Harmonizing rating scales}

Let us consider another instance where ex-post harmonization is called for. Some source variables measuring the same concept with Likert-type scales have different answer options in POLPAN than they do in RO-WVS. To achieve comparability, these variables could be linearly transformed into a common metric. Take as an example institutional trust. Both POLPAN and RO-WVS carry items about trust in parliament, legal system/courts, and political parties (in which the words zaufanie (Polish) and încredere (Romanian) were used, covering both English variants of trust and confidence). Respondents in POLPAN were offered a five point rating 
scale, while respondents in RO-WVS - a shorter, four point scale. The following linear transformation can be applied to make scales in the same matric: for the source $n$-point scale, for $k$ values ranging from 1 to $n, k$ may be recoded to new scale, with $l$ values from 1 to $m$, so that:

$$
l=(m-1) / n * 2+\mathrm{k}(m-1) / n
$$

As the methodology literature indicates, usually scales that have a middle point and are longer perform better (Gardner 1960, Alwin 1992, 1997, Krosnick and Fabrigar 1997, Østerås et al. 2008, Dawes 2008, Lundmark, Gilljam, and Dahlberg 2016; for a notable exception, see Revilla, Saris, and Krosnick 2014). In the case of institutional trust, the five point scale would be preferable over the four point scale (for specific comparison of four and five point rating scales, see Dawes 2002). After recoding, the POLPAN scale will go from 1 for very little or no trust, to 5 for very high degree of trust. Using the proposed formula, the RO-WVS item 1 (the lowest value) would be recoded to $(5-1) / 8+1 *(5-1) / 4=1 / 2+1=1 \frac{1}{2}$, the next value 2 to $(5-1) / 8+2 * 1=2 \frac{1}{2}, 3$ to $2 \frac{1}{2}$.and the last value 4 to $42 \frac{1}{2}$. Researchers can decide what common scale length to choose based on the provided general transformation or some other alternatives (some are considered in Dawes 2008).

Transformations such as scores from linear transformation are based on the assumption that the target variable $T$ is a function of the source variable $S, T=f(S)$. In general, the function $f$ could be any correspondence between original values of $\mathrm{S}$ which are transformed to T. The joint dataset of POLPAN and RO-WVS gives an opportunity for exploring the consequences for various types of variable transformation for substantive analysis. In particular, we suggest to explore the group confirmatory analysis to examine inter-country equivalence between postulated concepts. ${ }^{8}$

\section{Approaches for cross-country comparisons}

Both panel studies, POLPAN and RO-WVS, differ significantly in their design with respect to the sample composition, recruitment of respondents, and mode of data collection. We do not propose how to remedy these inter-study differences but highlight the challenges. The most conservative approach would be to perform analyses separately for two countries and compare the conclusion from the best country-specific models. On the other end of the possible spectrum of approaches, researchers make specific assumptions dealing with the effects of inter-study methodological differences and try to evaluate how they could influence substantive results. 
By pooling the weighted POLPAN and RO-WVS datasets to eliminate the impact of differences in sample sizes, one can account for cross-study differences. Consider a regression of the following type:

$$
\mathrm{Y} 2_{\mathrm{ij}}=\mathrm{a}+\mathrm{b}_{0} \mathrm{Y} 1_{\mathrm{ij}}+\mathrm{b}_{1} \mathrm{X} 1_{\mathrm{ij}}+\mathrm{b}_{2} \mathrm{X} 2_{\mathrm{ij}}+\mathrm{r}_{\mathrm{j}}+\mathrm{s}_{\mathrm{ij}}
$$

for individuals $i(1, \ldots, N$ in country $\mathrm{j}$ (Poland $=0$, Romania $=2)$. $Y$ is the dependent variable - such as interest in politics, political participation, democratic values, success in life, religiosity, or self-assessment of health (see Table 4) measured at time 1 (Y1) and time 2 (Y2); $\mathrm{X}$ refers to independent variables measured in time 1 (X1) and time 2 (X2); $r$ and $s$ refer to errors. Note that (1) is equivalent to:

$$
\mathrm{Y} 2_{\mathrm{ij}}-\mathrm{Y} 1_{\mathrm{ij}}=\mathrm{a}+\left(\mathrm{b}_{0}-1\right) \mathrm{Y} 1_{\mathrm{ij}}+\mathrm{b}_{1} \mathrm{X} 1_{\mathrm{ij}}+\mathrm{b}_{2} \mathrm{X} 2_{\mathrm{ij}}+\mathrm{r}_{\mathrm{j}}+\mathrm{s}_{\mathrm{ij}}
$$

which means that coefficients $b_{1}, \ldots, b_{4}$ can be interpreted as coefficients of change, showing to what extent the variables $\mathrm{X} 1, \ldots$ contribute to the difference $\mathrm{Y} 2_{\mathrm{ij}}-\mathrm{Y} 1_{\mathrm{ij}}$, if the initial state $\mathrm{Y} 1_{\mathrm{ij}}$ is controlled. This is exactly what is needed for studying change in dependent variables. The error term $r_{j}$ accounts for unobserved differences in both studies.

Based on these data, one can investigate how growing old, changing employment status, attaining additional education or moving on from one life stage to the next shape political values and behavior, religious practice or self-reported health - a core component of quality of life. This would yield interesting insights into the multiple relationships between culture and social structure in two EastCentral European countries that share many commonalities (e.g. decades under authoritarianism, significant social change after the 1989 revolutions), but feature also important differences, both prior to and after the 1989 systemic change.

\section{Conclusion}

The purpose of this article was to explore the possibility of using Polish and Romanian panel survey data for comparative research. Specifically, we presented the basic features of two datasets that cover a common time period and common substantive topics. For Poland, researchers can use waves 2013 and 2018 of the Polish Panel Survey POLPAN. For Romania, a corresponding dataset is the Romanian World Values Survey Panel (RO-WVS Panel) 2012 and 2018.

Topic overlap between these sources occurs mainly with political attitudes and behavior, specifically interest in politics, political participation, democratic values, and institutional trust. One social attitude, "success in life," can also be also compared. To test theories of within-person over-time change in political and 
social attitudes and behaviors, one can include a variety of socio-demographics, including gender, age, marital status, educational attainment, employment status, and locus of employment, as well as household composition (number of children in household and whether the respondent lives with their parents, as an enhanced measure of multi-generational families). Other variables core to social science research, religiosity and self-reported health, are also available, and can be used as outcomes of interest, or as explanatory variables, depending on researchers' interests.

Cross-national comparison remains an important endeavor. As Melvin R. Kohn, former president of the American Sociological Association, once remarked,

"cross-national research is valuable, even indispensable, for establishing the generality of findings and the validity of interpretations derived from singlenation studies. In no other way can we be certain that what we believe to be socialstructural regularities are not merely particularities, the product of some limited set of historical or cultural or political circumstances. I also argue that crossnational research is equally valuable, perhaps even more valuable, for forcing us to revise our interpretations to take account of cross-national differences and inconsistencies that could never be uncovered in single-nation research" (Kohn 1987: 713).

Indeed, one can also make this point about the comparison of panel surveys. Comparing panel survey data for two different cultural contexts that share some common features but also display substantial differences can shed light on how institutions shape the way social structure influences values and attitudes. By analyzing single-country panel data, we can understand whose situations change and due to what determinants, but we cannot know to what extent this change is due to some particular circumstances or is the result of more general processes that also work in other cultural contexts (see also the project described by Kiersztyn 2019). By comparing the mechanisms of intra-individual change in two different countries over time, we can understand the role the particular factors played in changing individuals and societies.

Post-communist countries of Central and Eastern Europe (CEE) are where the past and the present are both similar and different, and thus useful for analyses using longitudinal survey data. Prior to 1989, all societies shared the experience of State Socialism, yet there was room for substantial idiosyncrasies. The same holds for the post-communist environment in CEE. Even if we look no further than the 1980s, a period that a substantial part of respondents in both datasets have experienced, we note that, for example, farmers in Poland maintained private ownership of land, the country saw the rise of the Solidarity movement, and in the early 1980s, the imposition of martial law to quell the movement's protest. Romania had none of 
these. This is not to say it lacked particularities. We can easily point to the deep sultanistic nature of the Ceausescu regime and its wide-ranging consequences (see Linz and Stephan 1996). In 1989 both countries experienced revolutions and embarked on the transition to capitalism and democracy, they both saw the emergence of winners and losers of the transformation, high unemployment and rising inequality. Yet the nature of the revolutions themselves (peaceful in Poland, violent in Romania), and the paths Poland and Romania chose for transformation (shock therapy in Poland, an evolutionary approach in Romania) differed markedly. More recently, the 2008 economic crisis, while a pervasive force globally, affected Poland substantially less than Romania (see Tusk's 2010 "Green Island" speech, as cited in Tomescu-Dubrow et al 2018, p. 202). On similarities, both countries experience massive temporary migration, and are marred by corruption allegations and government infringement on democratic rule.

However, availability of comparative survey data in general (e.g. Slomczynski and Tomescu-Dubrow 2006; Kolczynska 2014; Wysmulek 2018), and of panel surveys in particular, is uneven in CEE. This is why the RO-WVS panel stands out as a unique resource that provides data on the nexus between social structure and cultural context. For now, this panel covers a quite limited time span, but keeping it alive for a long period would help researchers understand the Romanian society in the European context.

\section{NOTES}

1 For a comprehensive review and literature on the design and analytic uses of panel surveys, see e.g., Kasprzyk, Duncan, Kalton, and Singh 1989; Baltagi 2004; Halaby 2004; Andreß, Golsch, Schmidt, 2013; Pforr and Schröder 2016.

2 Examples of specialized panel surveys include European Union Statistics, on Income and Living Conditions, EU-SILC, conducted in ten Eastern and Baltic states since 2003 (Eurostat 2020), and country specific projects as Hungarian Household Panel Study 1991-1997 (TARKI 2020), Social Diagnosis 2000-2013: Objective and Subjective Quality of Life in Poland (University of Finance and Management 2020); see also the Quality of Life Survey run by Research Institute for the Quality of Life, Romanian Academy 1996-1998.

3 https://web.archive.org/web/20200321065555/http://www.worldvaluessurvey.org/wvs.jsp

4 POLPAN 2013 was funded by the Polish National Science Centre, Contract No. UMO2011/02/A/HS6/00238. In this wave the panel sample increased.

5 Response rates (RR) are calculated using the following formula:

$$
R R=\frac{I N T}{(N-N A-R D-N P)}
$$

where: $\mathrm{INT}=$ number of interviews, $\mathrm{N}=$ total sample size, $\mathrm{NA}=$ address not valid, $\mathrm{R}=$ respondent deceased, and $\mathrm{NP}=$ excluded from the population (living in the institution, emigrated abroad, or otherwise not in the target sample).

6 Depending on wave, cross-sectional analyses on POLPAN data require the use of weight variables. This is certainly the case for 2013 and 2018 samples. 
7 For a different approach to harmonizing religiosity questions, see Quandt and Bechert 2013; Biolcati, Molteni, Quandt and Vezzoni 2020. For harmonizing socio-demographic variables, see Hoffmeyer-Zlotnik 2016. General rules of harmonizing survey variables are provided in Granda and Blasczyk 2010, Granda, Wolf, and Hadorn 2010, Wolf, Schneider, Behr, and Joye 2016.

8 Davidov, Meuleman, Cieciuch, Schmidt, and Billiet 2014.

\section{REFERENCES}

Alwin, Duane F. (1992). Information transmission in the survey interview: Number of response categories and the reliability of attitude measurement. Sociological Methodology 22: 83-118. https://doi.org/10.2307/270993

Alwin, Duane F. (1997). Fling thermometers versus 7-point scales: Which are better? Sociological Methods \& Research 3 (25): 318-340. https://doi. org/10.1177/0049124197025003003

Alwin, Duane F. (2007). Margins of Errors: AStudy of Reliability in Survey Measurement. Hoboken, New Jersey: Wiley. https://doi.org/10.1002/9780470146316

Andreß, Hans-Jürgen, Katrin Golsch, and Alexande Schmidt. Eds. (2013). Applied Panel Data Analysis for Economic and Social Surveys. Berlin: Springer. https:// doi.org/10.1007/978-3-642-32914-2

Baltagi, Badi, Ed. (2004). Panel Data: Theory and Applications. Berlin: Springer.

Davidov, Eldad, Bart Meuleman, Jan Cieciuch, Peter Schmidt, and Jaak Billiet, Jaak (2014). Measurement equivalence in cross-national research. Annual Review of Sociology 40: 55-75. https://doi.org/10.1146/annurev-soc-071913-043137

Dawes, John. (2002). Five-point vs. eleven-point scales: Does it make a difference to data characteristics? Australasian Journal of Market Research 10 (1): 39-47.

Eurostat. (2020). European Union Statistics on Income and Living Conditions. Available at: https:/ec.europa.eu/eurostat/web/microdata/european-union-statisticson-income-and-living-conditions [Accessed March 29, 2020].

Garner, Wendell R. (1960). Rating scales, discriminability, and information transmission. Psychological Review 67 (6): 343-352. https://doi.org/10.1037/h0043047

Granda, Peter and Emily Blasczyk. 2010. Data Harmonization. Guidelines for Best Practices in Cross-Cultural Surveys. Ann Arbor, MI: Survey Research Center at the Institute for Social Research, University of Michigan.

Granda, Peter, Christof Wolf, and R. Hadorn (2010). Harmonizing survey data. Pp. 315-334 in Survey Methods in Multinational, Multiregional, and Multicultural Contexts, edited by Jannet Harkness, M. Braun, B. Edwards, T.P. Johnson, Lars Lyberg, Peter Mohler, B-E Pennell, and Tom Smith. New York: Wiley. https:/doi. org/10.1002/9780470609927.ch17

Groves, Robert M., and Lyberg, Lars E. (2010). Total survey error: Past, present, and future. Public Opinion Quarterly 74 (5): 849-879. https://doi.org/10.1093/poq/ nfq065

Halaby, Charles N. (2004). Panel models in sociological research: Theory into practice. Annual Review of Sociology 30: 507-544. https://doi.org/10.1146/annurev. soc.30.012703.110629 
Hoffmeyer-Zlotnik, Jurgen H. P. (2016). Standardisation and Harmonisation of SocioDemographic Variables. GESIS Survey Guidelines. Mannheim, Germany: GESIS - Leibniz Institute for the Social Sciences. https://doi.org/10.15465/gesis-sg_en_012 Hsiao, Cheng. (2007). Panel data analysis - advantages and challenges. Test 16 (1): 1-22. https://doi.org/10.1007/s11749-007-0046-X

Hsiao, Cheng. (2014). Analysis of Panel Data, 3rd ed. New York: Cambridge University Press. https://doi.org/10.1017/CBO9781139839327

Inglehart, Ronald. (1997) Modernization and Postmodernization, Princeton: Princeton University Press. https://doi.org/10.2307/j.ctv10vm2ns

Inglehart, Ronald. (2018). Cultural Evolution. People's Motivations are Changing and Reshaping the World. Cambridge: Cambridge University Press. https:/doi. org/10.1017/9781108613880

Inglehart, Ronald and Christian Welzel. (2005). Modernization, Cultural Change, and Democracy: The Human Development Sequence. Cambridge: Cambridge University Press.

Kasprzyk, Daniel, Greg Duncan, Graham Kalton, and M. P. Singh, Eds. (1989). Panel Surveys. New York: Wiley

Kiersztyn, Anna. (2019). The cross-national biographies: Young (CNB-Young) project. Harmonizing panel data for the study of youth employment precarity. Harmonization: Newsletter on Survey Data Harmonization in the Social Sciences 5 (2): 41-42.

Kohn, Melvin. L. (1987). Cross-national research as an analytic strategy: 1987 Presidential Address. American Sociological Review 52 (6): 713-731. https://doi. org/10.2307/2095831

Kołczyńska, Marta.(2014). Representation of Southeast European countries in international survey projects: Assessing data quality. Ask: Research and Methods 23(1): 57-78.

Krosnick, Jon and Leandre R Fabrigar. (1997). Designing rating scales for effective measurement in surveys. Pp 141-164 in Survey Measurement and Process Quality, edited by Lars Lyberg, E. Paul P. Biemer, Martin Collins, Edith D. de Leeuw, Cathryn Dippo, Norbert Schwarz, Dennis Trewin. New York, NY: John Wiley.

Laurie, Heather. 2003. From PAPI to CAPI: consequences for data quality on the British Household Panel Study, ISER Working Paper Series, No. 2003-14. Available online at https://www.econstor.eu/bitstream/10419/92209/1/2003-14.pdf (last accessed October 1, 2020)

Linz, Juan J., and Alfred Stepan. (1996). Problems of democratic transition and consolidation: Southern Europe, South America, and post-communist Europe. JHU Press.

Lyberg, Lars E. and D.M. Stukel. (2010). Quality assurance and quality control in cross-national comparative studies. Pp.225-249 in Survey Methods in Multinational, Multiregional, and Multicultural Contexts, edited by Janet A. Harkness, Michael Braun, Brad Edwards, Timothy P. Johnson, Lars Lyberg, Peter Ph. Mohler, BethEllen Pennell, and W Tom Smith. Ney York, NY: John Wiley \& Sons Inc. https:// doi.org/10.1002/9780470609927.ch13

Lyberg, Lars E., and Weisberg, H. (2016). Total survey error: A paradigm for survey methodology. Pp. 27-42 C. Wolf, D. Joye, T. Smith, \& Y. Fu, The SAGE Handbook of Survey Methodology (pp. 27-42). London, UK: SAGE. https://doi. org/10.4135/9781473957893.n3 
Østerås, Nina., Pål Gulbrandsen, Andrew Garratt, Jūratë Šaltytë Benth, Fredrik A. Dahl, Bård Natvig, and Søren Brag. (2008). A randomised comparison of a four- and a fivepoint scale version of the Norwegian Function Assessment Scale. Health Quality and Life Outcomes 6 (14): 2-9. https://doi.org/10.1186/1477-7525-6-14

Quandt, Markus and Insa Bechert. (2013) Assessing trends in religiosity with ISSP data. Pp. 89-98 in ISSP Data Report: Religious Attitudes and Religious Change, edited by Insa Bechert and Markus Quandt. (GESISSchriftenreihe, 13). Köln: GESIS Leibniz-Institut für Sozialwissenschaften. https://doi.org/10.21241/ssoar.37204

Pforr, Klaus and Jette Schröder. (2016). Why Panel Surveys? GESIS Survey Guidelines. Mannheim, Germany: GESIS - Leibniz Institute for the Social Sciences. http://doi. org/10.15465/gesis-sg_en_008

Revilla, Melanie A., Willem E. Saris, and Jon A. Krosnick. (2014). Choosing the number of categories in Agree-Disagree scales. Sociological Methods \& Research 43(1):73-97. https://doi.org/10.1177/0049124113509605

Schräpler, Jörg-Peter, Jürgen Schupp, and Gert G. Wagner. (2010). Changing from PAPI to CAPI: Introducing CAPI in a longitudinal study. Journal of Official Statistics 26 (2): 239-269.

Schmidt-Catran, Alexander W. and Malcom Fairbrother, M. (2015). The random effects in multilevel models: Getting them wrong and getting them right. European Sociological Review 32(1): 23-38. https://doi.org/10.1093/esr/jcv090

Slomczynski, Kazimierz M. and Irina Tomescu-Dubrow. 2006. Representation of European post-communist countries in cross-national public opinion surveys." Problems of PostCommunism 53 (4): 42-52. https://doi.org/10.2753/PPC1075-8216530404

Slomczynski, Kazimierz M, Irina Tomescu-Dubrow, Joshua Kjerulf Dubrow. 2015. Changes in social structure, class, and stratification: The Polish Panel Survey (POLPAN). ASK: Research and Methods 24: 19-37.

Slomczynski, Kazimierz M., Irina Tomescu-Dubrow, J. Craig Jenkins with Marta Kołczyńska, Przemek Powałko, Ilona Wysmułek, Olena Oleksiyenko, Marcin Zielińsk and Joshua K. DUbrow. (2016). Democratic Values and Protest Behavior: Harmonization of Data from International Survey Projects. Warsaw: IFiS Publishers. University of Finance and Management. (2020). Social Diagnosis 2000-2013: Objective and Subjective Quality of Life in Poland. Available at: http://www.diagnoza.com/ index-en.html [Accessed March 29, 2020]

TARKI. 2020. Hungarian Household Panel Study (1992-1997). Available at: https://tarki. hu/eng/hungarian-household-panel-study-1992-1997 [Accessed March 29, 2020]

Tomescu-Dubrow, Irina, Kazimierz M. Slomczynski, Henryk Domanski, Joshua Kjerulf Dubrow, Zbigniew Sawinski, and Dariusz Przybysz. 2018. Dynamics of Class and Stratification in Poland. Budapest: CEU Press.

Wolf, Christof, Silke L. Schneider, Dorothée Behr, and Dominique Joye. (2016). Harmonizing survey questions between cultures and over time. Pp. 502-524 in The SAGE Handbook of Survey Methodology, edited by Christof Wolf, Dominique Joye, Tom W. Smith, and Yang-chi Fu. London, UK: SAGE. https://doi.org/10.4135/9781473957893.n33

Wysmułek, Ilona. 2018. Europe of uneven data: Country representation in international surveys on corruption, 1989-2017. Ask: Research \& Methods 27: 87-104. https:// doi.org/10.18061/ask.v27i1.0005 


\section{APPENDIX A}

\section{Items Overlap in POLPAN 2013-2018 and RO-WVS Panel 2012-2018}

\begin{tabular}{ll}
\hline \multicolumn{1}{c}{ POLPAN } & RO-WVS \\
\hline POLPAN 2013 and POLPAN 2018: Filled in by the & RO-WVS 2012 and RO-WVS Panel 2018: Filled in \\
by the interviewer. \\
interviewer. & (1) Male \\
$\begin{array}{ll}\text { (1) Male } & \text { (2) Female } \\
\text { (2) Female } & \end{array}$
\end{tabular}

Year of birth/Age

POLPAN 2013: Year of birth [from sample records] RO-WVS 2012 and RO-WVS 2018: Can you tell POLPAN 2018: In what year were you born? me your year of birth, please?

POLPAN 2018: Age [Computed]

$19 \quad$ (write in last two digits)

RO-WVS 2018: Age [Can be derived]

\section{Marital Status}

\begin{tabular}{ll}
\hline POLPAN 2013 and POLPAN 2018: What is your & RO-WVS Panel 2012 and RO-WVS 2018: Are you \\
marital status? & currently: \\
(1) Never married & (1) Married \\
(2) Married & (2) Living together as married \\
(3) Divorced & (3) Divorced \\
(4) Widowed & (4) Separated \\
(5) Other & (5) Widowed \\
& (6) Single \\
\hline
\end{tabular}

Presence of Children in the Household

POLPAN 2013 and POLPAN 18: I would now like RO-WVS 2012 and RO-WVS 2018: Have you had to ask about members of your household. What is any children? (Coding 0 if no children):

the relationship of these persons to you? [Child: son

/ daughter is an option. Researchers can establish the number of children from the table of household members].
(0) No children
(1) One child
(2) Two children
(3) Three children
(4) Four children
(5) Five children
(6) Six children
(7) Seven children
(8) Eight or more children

(0) No children

(1) One child

(2) Two children

(3) Three children

(4) Four children

(5) Five children

(6) Six children

(7) Seven children

(8) Eight or more children

Living with Parents

POLPAN 2013 and POLPAN 2018: I would now like RO WVS Panel 2012: Do you live with your parents? to ask about members of your household. What is the relationship of these persons to you? [Parents: father / mother, and father-in-law / mother-in-law are options]
(1) Yes
(2) Yes, own parent(s)
(3) Yes, parent(s) in law
(4) Yes, both own parent(s) and parent(s) in law

(1) Yes

(2) No

RO WVS Panel 2018: Do you live with your parents or your parents in law? (Code one answer):
(1) Yes
(2) Yes, own parent(s)
(3) Yes, parent(s) in law
(4) Yes, both own parent(s) and parent(s) in law 


\section{Respondent's Educational Attainment}

POLPAN 2013 and POLPAN 2018: I would like to RO WVS Panel 2012: What is the highest eduask you about your education. What is your highest cational level that you have attained? [NOTE: if level of completed education? respondent indicates to be a student, code highest

(01) Elementary not completed, or no school education

(02) Elementary completed - gymnasium middle school / after 2000 only

(03) Basic vocational

(04) General high school without diploma

(05) General high school with diploma

(06) Vocational high school without diploma

(07) Vocational high school with diploma

(08) Post high school without diploma

(09) Post high school with diploma

(10) College type, equivalent of BS or BA

(11) University type, MA or equivalent of MA level s/he expects to complete]:

(1) No formal education

(2) Incomplete primary school

(3) Complete primary school

(4) Incomplete secondary school: technical/ vocational type

(5) Complete secondary school: technical/vocational type

(6) Incomplete secondary: university-preparatory type

(7) Complete secondary: university-preparatory type

(8) Some university-level education, without degree

(9) University-level education, with degree

RO WVS Panel 2018: What is the highest educational level that you, your spouse, your mother and your father have attained?

(0) Early childhood education (ISCED 0) / no education

(1) Primary education (ISCED 1)

(2) Lower secondary education (ISCED 2)

(3) Upper secondary education (ISCED 3)

(4) Post-secondary non-tertiary education (ISCED 4)

(5) Short-cycle tertiary education (ISCED 5)

(6) Bachelor or equivalent (ISCED 6)

(7) Master or equivalent (ISCED 7)

(8) Doctoral or equivalent (ISCED 8)

Employment Status

POLPAN 2013 and POLPAN 2018: A series of detailed items to be combined to determine:

Paid employment:

(1) Full time employee (30 hours a week or more)

(2) Part time employee (less than 30 hours a week)

(3) Self employed

No paid employment:
(4) Retired/pensioned
(5) Housewife not otherwise employed
(6) Student
(7) Unemployed

RO WVS Panel 2012: Are you employed now, or not?:

Paid employment:

(1) Full time employee (30 hours a week or more)

(2) Part time employee (less than 30 hours a week)

(3) Self employed

No paid employment:
(4) Retired/pensioned
(5) Housewife not otherwise employed
(6) Student
(7) Unemployed

Locus of Employment

POLPAN 2013 and POLPAN 2018: A series of detailed items to be combined to determine "locus of employment."
(1) Government or public institution
(2) Private business or industry
(3) Private non-profit organization

RO-WVS 2012 and RO-WVS: Are you working for the government or public institution, for private business or industry, or for a private non-profit organization? If you do not work currently, characterize your major work in the past! Do you or did you work for (read out and code one answer):

(1) Government or public institution

(2) Private business or industry

(3) Private non-profit organization 
Interest in Politics

POLPAN 2013 and POLPAN 2018: To what extent RO-WVS 2012 and RO-WVS: How interested are you interested in politics?

would you say you are in politics? Are you...
(1) To a very high extent (you follow very care- fully what happens in politics)
(2) To a high extent (you follow carefully what happens in politics)
(3) To a moderate extent (you follow only big events)
(4) To a low extent
(5) Not interested in politics at all

(1) Very interested

(2) Somewhat interested

(3) Not very interested

(4) Not at all interested

\section{Political Participation}

POLPAN 2013: In the past 12 months, have you: - participated in any demonstration, gathering or street protest?

(1) Yes

(2) No

(8) Don't know

- signed any petition addressed to state administration representatives or an open letter regarding public matters?
(1) Yes
(2) No
(8) Don't know

- in any other way been active in public (social) affairs regarding the whole country or voivodship (province)?
(1) Yes
(2) No
(8) Don't know

- regarding the (city) district, community or county level?
(1) Yes
(2) No
(8) Don't know

POLPAN 2018: In the past 12 months, have you: - participated in any demonstration, gathering or street protest?
(1) Yes
(2) No
(8) Don't know

- signed any petition addressed to state administration representatives or an open letter regarding public matters?
(1) Yes
(2) No
(8) Don't know

- in any other way been active in public (social) affairs:
(1) Yes
(2) No
(8) Don't know

RO-WVS 2018: Now l'd like you to look at this card. I'm going to read out some forms of political action that people can take, and l'd like you to tell me, for each one, whether you have done any of these things, whether you might do it or would never under any circumstances do it.

- Signing a petition
(1) Have done
(2) Might do
(3) Would never do
- Joining in boycotts
(1) Have done
(2) Might do
(3) Would never do

- Attending peaceful demonstrations
(1) Have done
(2) Might do
(3) Would never do

- Joining strikes
(1) Have done
(2) Might do
(3) Would never do

RO-WVS 2018: Tell me for each of these activities how often you have done it in the last year - Signing a petition
(1) Not at all
(2) Once
(3) Twice
(4) Three times
(5) More than three times

-- Attending peaceful demonstrations

(1) Not at all

(2) Once

(3) Twice

(4) Three times

(5) More than three times

-- Any other act of protest
(1) Not at all
(2) Once
(3) Twice
(4) Three times
(5) More than three times 


\section{Democratic Values}

POLPAN 2013 and POLPAN 2018: I will now read RO-WVS 2012 and RO-WVS 2018: I'm going to to you various sentences. After each sentence, please tell me whether you strongly agree, somedescribe various types of political systems and ask what agree, neither agree nor disagree, somewhat ing this country. For each one, would you say it is disagree, or strongly disagree. I am interested in your first reactions towards these statements. If the country is governed by a wise leader, he or she need not obey the law.
(1) Strongly agree
(2) Somewhat agree
(3) Neither agree nor disagree
(4) Somewhat disagree
(5) Strongly disagree a very good, fairly good, fairly bad or very bad way of governing this country?

Having a strong leader who does not have to bother with parliament and elections.
(1) Very good
(2) Fairly good
(3) Fairly bad or very bad way of governing this country

\section{Success in Life}

POLPAN 2013 and POLPAN 2018: Now, I would like RO-WVS 2012 and RO-WVS 2018: Now l'd like to talk about factors that, according to you, contributeyou to tell me your views on various issues. How to success in life. To what extent, in your opinion, arewould you place your views on this scale? 1 means certain things important for achieving success in life? you agree completely with the statement on the left; - knowing the right people

(1) Absolutely necessary

(2) Very important

(3) Somewhat important

(4) Somewhat unimportant

(5) Not at all important - hard work

(1) Absolutely necessary

(2) Very important

(3) Somewhat important

(4) Somewhat unimportant - luck

(5) Not at all important

(1) Absolutely necessary

(2) Very important

(3) Somewhat important

(4) Somewhat unimportant

(5) Not at all important
10 means you agree completely with the statement on the right; and if your views fall somewhere in between, you can choose any number in between

- [1] In the long run, hard work usually brings a better life to [10] Hard work doesn't generally bring success-it's more a matter of luck and connections

$$
\text { Institutional trust }
$$

POLPAN 2013 and POLPAN 2018: Now, I will list RO-WVS 2012 and RO-WVS 2018: I am going to various institutions. Please indicate to what extent you have trust in them.

- Parliament
(1) To very high extent
(2) To high extent
(3) To moderate extent
(4) To a low extent
(5) Very little or not at all

- The courts
(1) To very high extent
(2) To high extent
(3) To moderate extent
(4) To a low extent
(5) Very little or not at all

- Political parties
(1) To very high extent
(2) To high extent
(3) To moderate extent
(4) To a low extent
(5) Very little or not at all

name a number of organizations. For each one, could you tell me how much confidence you have in them: is it a great deal of confidence, quite a lot of confidence, not very much confidence or none at all?

- Parliament

(1) A great deal

(2) Quite a lot

(3) Not very much

(4) Not at all

- The courts

(1) A great deal

(2) Quite a lot

(3) Not very much

(4) Not at all

- Political parties

(1) A great deal

(2) Quite a lot

(3) Not very much

(4) Not at all 


\section{Religiosity}

POLPAN 2013 and POLPAN 2018: Apart from special situations, like weddings or funerals, how frequently do you participate in church service?

(1) Never, not at all

(2) Less frequently than once a month

(3) Less frequently than once a week, but at least once a month,

(4) Usually once a week

(5) More frequently than once a week?
RO-WVS I 2012 and RO-2018: Apart from weddings and funerals, about how often do you attend religious services these days? (Code one answer):

(1) More than once a week

(2) Once a week

(3) Once a month

(4) Only on special holy days

(5) Once a year

(6) Less often

(7) Never, practically never

Subjective evaluation of health

POLPAN 2013 and POLPAN 2018: How do you evaluate the state of your physical health in comparison with the state of physical health of the majority of people your age? Is the state of your physical health:

(1) Much better than the state of health of other people at your age,

(2) Somewhat better,

(3) Somewhat worse, or

(4) Much worse than the state of health of other people your age?

(5 - About the same)

[8 - don't know, difficult to say]

POLPAN 2013 and POLPAN 2018: How would you evaluate your psychological state? Generally, would you say that your psychological state is: CARD P17
(1) Very good,
(2) Somewhat good
(3) Somewhat bad
(4) Very bad?
[8-don't know, difficult to say]

RO-WVS Panel 2012: All in all, how would you describe your state of health these days? Would you say it is:
(1) Very good
(2) Good
(3) Fair
(4) Poor

RO-WVS Panel 2018: All in all, how would you describe your state of health these days? Would you say it is:
(1) Very good
(2) Good
(3) Fair
(4) Poor
(5) Very poor 
